FIG. 4 Southern blots prepared using genomic DNA from different $M$. tuberculosis strains, digested with $K p n l$, were probed with a, katG (the $4.5-\mathrm{kb}$ $K p n i$ fragment), and $b$, the sodA gene (1.1-kb EcoRl-Kpnl fragment; ref. 18). Labelling of probes and processing of blots was as described ${ }^{15}$. Lane 1. H37Rv; lane 2, strain 12, $\mathrm{IC}_{\min } 1.6 \mu \mathrm{g} \mathrm{ml} \mathrm{I}^{-1} \mathrm{INH}$; lane 3, B1453, IC $C_{\min }>50 \mu \mathrm{g} \mathrm{ml}^{-1} \mathrm{INH}^{20}$; lane 4, strain $24, \mathrm{IC}_{\min }>50 \mu \mathrm{g} \mathrm{ml}^{-1} \mathrm{INH}$; lane 5, 79112, INH-sensitive ${ }^{21}$; lane 6, 12646, INH-sensitive ${ }^{21}$; lane 7,79665 , INH-sensitive ${ }^{21}$. INH susceptibilities were confirmed by inoculation of LowensteinJensen slopes containing differing concentrations of $\mathbb{I N H}$.

multiple-drug-resistant strains in which there is a correlation between INH resistance and decreased catalase activity are particularly important because, owing to the contagiousness of tuberculosis, these strains pose a public health threat to both

Received 13 May; accepted 2 July 1992.

1. Murray, C. J. L., Styblo, K. \& Rouillon, A. Bull. Int. Union against Tuberculosis and Lung Disorders 65, 6-24 (1990).

2. Perriens, J. H. et al. Am. Rev. respir. Dis. 144, 750-755 (1991)

3. Snider, D. E. \& Roper, W. L. New Engl. L. Med. 326, 703-705 (1992).

4. Cohn, M. L., Kovitz, C., Oda, U. \& Middlebrook, G. Am. Rev. Tuberc. 70, 641-664 (1954).

5. Middlebrook, G., Cohn, M. L. \& Scheffer, W. B. Am. Rev. Tuberc. 70, 852-872 (1954).

6. Youatt, J. Am. Rev, respir. Dis. 99, 729-749 (1969).

7. Winder, F. G. in The Biology of the Mycobacteria Vol. 1 (eds Ratledge, C. \& Stanford, J.) 353-438 (Academic, London, 1982).

8. Snapper, S. B. et al. Proc. natn. Acad. Sci. U.S.A. 85, 6987-6991 (1988).

9. Snapper, S. B., Melton, R. E., Mustafa, S., Kieser. T. \& Jacobs, W. R. Molec. Microbiol. 4, 1911-1919 (1990).

10. Heym, B. \& Cole, S. T. Res. Microbiol. (in the press).

11. Gayathri Devi, B., Shaila, M. S., Ramakrishnan, T. \& Gopinathan, K. P. Biochem. J. 149, 187-197 (1975).
HIV-infected and healthy individuals ${ }^{3}$. An improved understanding of the mechanisms of drug resistance will enable rapid tests for drug-resistance isolates to be developed and should facilitate the design of antituberculosis drugs.

\section{Anatomy of a transcription factor important for the Start of the cell cycle in Saccharomyces cerevisiae}

\section{Michael Primig, Shanthini Sockanathan, Herbert Auer \& Kim Nasmyth}

Institute of Molecular Pathology, Dr Bohr-Gasse 7, A-1030 Vienna, Austria

ENTRY of yeast cells into the mitotic cell cycle (Start) involves a form of the CDC28 kinase that associates with G1-specific cyclins encoded by $C L N 1$ and $C L N 2$ (ref. 1). The onset of Start may be triggered by the activation of $C L N 1$ and $C L N 2$ transcription in late G1 (ref. 2). SWI4 and SWI6 are components of a factor (SBF) that binds the CACGAAAA (SCB) promoter elements ${ }^{3-5}$ responsible for activation in late $\mathrm{Gl}$ of the $\mathrm{HO}$ endonuclease, $C L N 1$ and $C L N 2$ genes ${ }^{6,7}$. A related factor (MBF) containing SWI6 and a 120K protein ${ }^{8}$ binds to the ACGCGTNA (MCB) promoter elements responsible for late G1-specific transcription of DNA replication genes ${ }^{9-12}$. Nothing is known about how these heteromeric proteins bind DNA. We show here that SWI4 contains a novel DNA-binding domain at its $\mathbf{N}$ terminus that alone binds specifically to SCBs and a C-terminal domain that binds to SWI6. SWI4's DNA-binding domain is similar to an N-terminal domain of the cdc10 protein that is a component of an MBF-like factor from Schizosaccharomyces pombe $e^{13}$ and is required for Start ${ }^{14,15}$. An involvement of this kind of DNA-binding domain in transcriptional controls at Start may therefore be a conserved feature of eukaryotic cells.
12. Triggs-Raine, B. L., Doble, B. W., Mulvey, M. R., Sorby. P. A. \& Loewen, P. C. J. Bact. 170, 4415-4419 (1988).

13. Loprasert, S., Negoro, S. \& Okada, H. J. Bact. 171, $4871-4875$ (1989).

14. Mulvey, M. R., Sorby, P. A., Triggs-Raine, B. L. \& Loewen, P. C. Gene 73, 337-345 (1988)

15. Zhang, $Y$. et al. infect. Immun. 60, 2160-2165 (1992).

16. Quemard, A., Lacave, C. \& Laneelle, G. Antimicr. Ag. Chemother. 35, 1035-1039 (1991).

17. Shoeb, H. A., Bowman, B. U., Ottolenghi, A. O. \& Merola, A. J. Antimicr. Ag. Chemother. 27, 404-407 (1985).

18. Zhang, Y., Lathigra, R., Garbe, T., Catty, D. \& Young, D. Molec. Microbiol. 5, 381-391 (1991).

19. Wayne, L. G. \& Diaz, G. A. Analyt. Biochem. 157, 89-92 (1986).

20. Jackett, P. S., Aber, V. \& Lowrie, D. J. gen. Microbiol. 104, 37-45 (1978).

21. Mitchison, D. A., Selkon, J. B. \& Lloyd, J. J. Path. Bact. 86, 377-386 (1963).

ACKNOWLEDGEMENTS. We thank W. R. Jacobs and P. C. Loewen for strains, and J. Grosset, R. Lathigra, $T$. Garbe and J. Ivanyi for discussion and encouragement. This work was supported by the World Health Organization Programme for Vaccine Development (D.Y. and S.C.), the Fondation pour la Recherche Medicale (S.C.), and the Association Française Raoul Follereau (S.C.).
To determine whether SWI4 or SWI6 alone can bind SCBs, we translated both proteins in reticulocyte lysates. Full-length SWI6 (846 residues ${ }^{16}$ ) is made efficiently but much of SWI4 $\left(1,094\right.$ residues $\left.^{4,17}\right)$ is either degraded or prematurely terminated (Fig. 1a). We tested the ability of the proteins to bind an oligonucleotide from the CLN2 promoter (pCL2) that contains three potential SCBs and forms a complex with SBF isolated from yeast ${ }^{6}$. Using a gel retardation assay, we observe a heterogenous set of SWI4: pCL2 complexes (Fig. 1b), all of which are recognized by a SWI4-specific antibody but not by preimmune serum (data not shown and Fig. 1c). The heterogeneity may be due to the variable size of the SWI4 protein. No complexes were observed using the SWI6 protein (Fig. 1b). That SWI4 but not SWI6 can bind SCB DNA is consistent with experiments showing that SWI4 overproduction allows $H O$ to be transcribed without SWI6 ${ }^{17,18}$ (but not vice versa) and that $C L N 2$ can be partially activated by SWI4 in swi6 mutants ${ }^{6,19}$.

Cotranslated SWI4 and SWI6 proteins form a new complex (with pCL2) containing both proteins that migrates with a mobility similar to that of the complexes formed by partially purified SBF from yeast (Fig. $1 b, c$ ). The complex formed with in vitro translated proteins seems to migrate slightly faster than that formed by yeast proteins and could conceivably lack a third component or modification. A truncated version of SWI4 lacking 144 amino acids from its C-terminal end (SWI4E) cannot form complexes with SWI6 although it still binds pCL2 (Fig. 1d). $H O$ expression due to modest overproduction of such a protein in yeast is largely SWI6-independent ${ }^{17}$. Likewise, a version of SWI6 lacking its most C-terminal 89 amino acids (SWI6C) cannot form complexes on pCL2 with SWI4 (Fig. 1e). SWI4 and SWI6 might therefore interact by their $\mathrm{C}$ termini. This part of SWI6 is highly conserved in Kluyveromyces lactis 
FIG. 1 Binary and ternary complexes formed by SWI4 and SWI6 on SCB DNA. $\mathrm{fp}$, Free probe. a, Translation products labelled with ${ }^{35}$ S-Methionine and examined on SDS polyacrylamide gels $^{24}$. SWI4E refers to a truncated form of SWI4 lacking its C-terminal 144 amino acids due to digestion of the DNA template with EcoRI. SWI6C refers to a version of SWI6 that lacks its C-terminal 89 amino acids due to digestion of the DNA template with Clal. SWI4's predicted $M_{\mathrm{r}}$ is $123 \mathrm{~K}$ but it runs as a $150 \mathrm{~K}$ protein. $b$, SWI4 binds DNA and recruits SWI6. Labelled DNA $(0.5 \mathrm{ng})$ was incubated with $10 \mu \mathrm{l}$ reticulocyte lysates containing SWI6 (lane 1), SWI4 (lane 2) and both proteins (lanes 3 and 4). Four times less SWI4 RNA was added to the translation mix in lane 4 compared to lane 3 . Note that the ternary complexes containing SWI4 and SWI6 are much more uniform than the binary complexes containing SWI4 alone. We presume that this is due to the involvement of SWI4's C-terminus in its interaction with SWI6 (see d); that is very few of the incomplete SWI4 molecules will be able to form ternary complexes. c, In vitro SWI4-SWI6 complexes are recognized by SWI4- and SWI6-specific antibodies and have a similar electrophoretic mobility to in vivo complexes (marked c). Yeast SBF $(1 \mu l)$ purified by heparin agarose chromatography (hep frac) was incubated with $0.5 \mathrm{ng}$ labelled probe (lane 5). A reticulocyte lysate containing both SWI4 and SWI6 (lanes 6 to 8) was mixed with $1 \mu$ l preimmune serum (lane $6)$, anti-SWI4 serum ${ }^{8}$ (lane 7) and antiSW16 serum ${ }^{5}$ (lane 8 ). d, The Cterminus of SWI4 is required for interaction with SWI6. Labelled probe $(0.5 \mathrm{ng})$ was incubated with $10 \mu \mathrm{l}$ lysates containing SWI4 (lane 13), SWI4E (lane 12), SWI6 (lane 11) as well as SWI4 and SWI4E cotranslated with SWI6 (lanes 10 and 9). Lysate alone (not shown) gave the same pattern as SWI6 protein. $e$, The $C$ terminus of SWI6 is required for interaction with SWI4. Labelled probe $(0.5 \mathrm{ng})$ was incubated with $10 \mu$ l lysates containing SWI6C (lane 14), SWI4 (lane 15), SWI6C plus SWI4 (lane 16), and SWI6 plus SWI4 (lane 17). $f$, The C terminus of SWI4 is sufficient for interaction with SWI6. Labelled probe $(0.5 \mathrm{ng})$ was incubated with a control lysate (lane 18), with SWI4NC1 (lanes 19-21) and SWI4NC2 (lanes 22 and 23). SWI6 $(0.2 \mu \mathrm{g})$ purified from $E$. coli ${ }^{5}$ (S6Eco) was added in lanes $20-23$ as indicated at the bottom of the panel. Preimmune serum $(1 \mu l)$ diluted 1:10 was added in lanes 20 and 22. SWI6 antiserum diluted 1:10 was added in lanes 21 and 23. The SWI4NC-dependent complexes are marked S4NC1 and S4NC2. The SWI4NC1:SW16 complexes are only partially abolished by SWI6 anti-serum because of the large amount of SWI6 protein present.

METHODS. RNA synthesized by T7 RNA polymerase ${ }^{25}$ was added to a rabbit reticulocyte lysate system (Promega L4210) at concentrations of 10$50 \mu \mathrm{g} \mathrm{ml} \mathrm{l}^{-1}$. SWI4 RNA was synthesized at a 30 -fold molar excess of ${ }^{m 7}$ GpppG CAP analogue (Pharmacia) versus rGTP. Labelled oligonucleotide $(0.5 \mathrm{ng})$ and 3-15 $\mu /$ reticulocyte lysate was incubated in $20 \mathrm{mM}$ Tris $\mathrm{pH} 7.5$, $3 \mathrm{mM} \mathrm{MgCl}_{2}, 1 \mathrm{mM}$ DTT, $50 \mathrm{mM} \mathrm{NaCl}, 0.1 \mathrm{mM}$ EDTA, $5 \mathrm{mM}$ spermidine, $50 \mu \mathrm{g} \mathrm{ml}{ }^{-1}$ BSA, $0.5 \mu \mathrm{g} \mathrm{ml}^{-1}$ salmon sperm DNA and $5 \%$ glycerol for 15-30 min in a final volume of $20 \mu \mathrm{l}$. For each $\mu \mathrm{l}$ of lysate, $0.5 \mu \mathrm{g}$ Poly $d(I) . d(C)$ from Pharmacia was added. Complexes were analysed on 4\% 20:1 acrylamide: bisacrylamide gels in $0.25 \times$ TBE buffer $(1 \times$ TBE is $89 \mathrm{mM}$ Tris, $89 \mathrm{mM}$ borate and $2.4 \mathrm{mM}$ EDTA) that were prerun at $10 \mathrm{~V} \mathrm{~cm}^{-1}$ for $1 \mathrm{~h}$. In competition experiments, unlabelled oligonucleotides were added at a 500 -
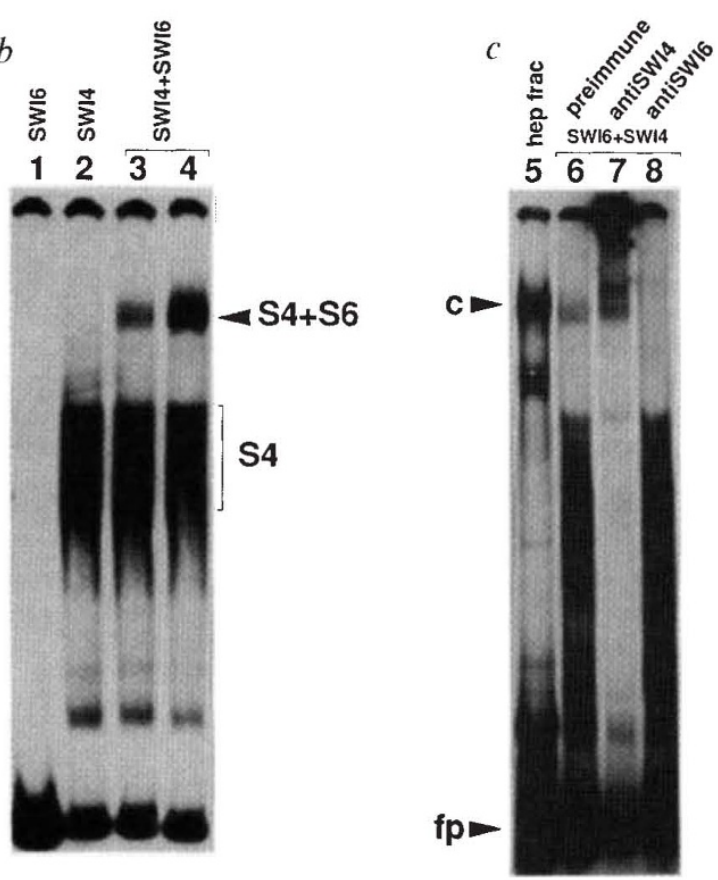

$e$
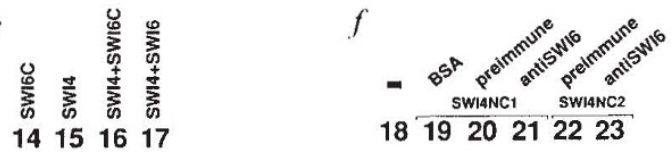

$1 8 \longdiv { 1 9 2 0 2 1 } 2 2 2 3$

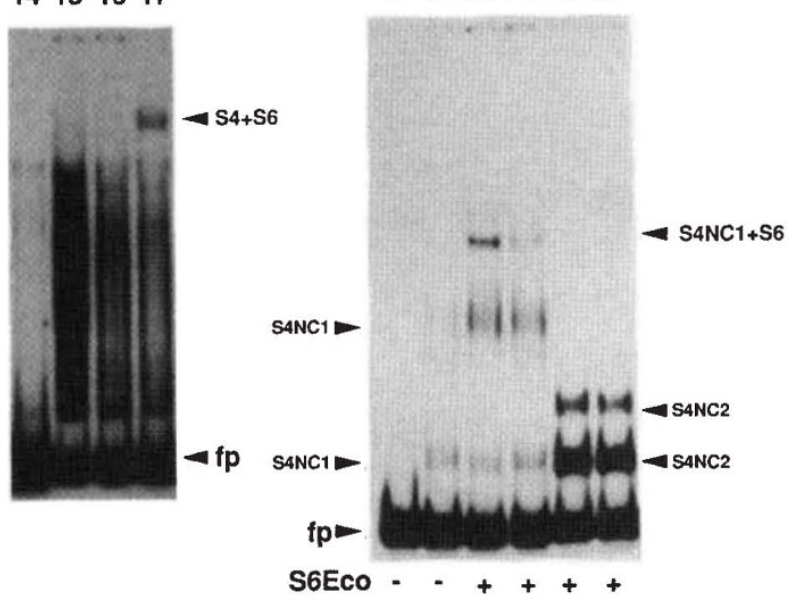

fold molar excess before addition of the lysate samples. Antibodies were added last (10 min before electrophoresis ). Gels were run at $10 \mathrm{~V} \mathrm{~cm}^{-1}$ dried and exposed overnight at $-80^{\circ} \mathrm{C}$ with an intensifying screen. The following oligonucleotides were used to construct the in vitro expression vectors of SWI4, SWI6, SWI4NC1 and SWI4NC2: SWI6-1, taattcgaattccCATGGCGTTGGAAGAAG; SWI6-2, aaaatttcgaaggaggaaatggCCAGTCTC; SWI4-1, gatccgggCCATTTGATGTITTGATATCAA; SWI4-2, tcgatcagatctITATGCGTTTGCCCTCAA; SWI4-A, ttggcgctgcaGTGTAGCTCGATGGAGAAG; SWI4-B, gatcgactgcaGAAAAGCAAAATITTATTC; SWI4-C, gatcgactgcaGAGACGTTGAGACTAGCAA; To construct the SWI6 expression plasmid, pT7 $755-1024$ was linearized with $\mathrm{Ncol}$ and $\mathrm{BamHI}$ and triple ligated to a SWI6 PCR fragment cut with $\mathrm{Ncol}$ and $\mathrm{MScl}$ plus a $\mathrm{Mscl}-\mathrm{SW} / 6-\mathrm{Bg} / \mathrm{ll}$ restriction fragment from pBd159 (a SWI6 Hindlll fragment cloned into the Hindlll site of $\mathrm{plC19H}$ ). To obtain the SWI4 vector, $\mathrm{pT}_{755-1024}$ was digested with $\mathrm{Ncol}$, end repaired with Klenow and redigested with $B a m H I$. The linearized plasmid was ligated to a SWI4 PCR fragment that was digested with HaellI and Bg/II. The SWI4NC1 fusion was a triple ligation of 2 PCR fragments obtained with the oligonucleotides SW14 $\Delta 8$ and SWI4-A as well as SWI4-B and SWI4-2; the former was cut with $\mathrm{Ncol}$ and Pstl, the latter with Pstl and Bg/l and ligated to $\mathrm{pT} 7_{755-1024}$ treated as described for SWI6. SWI4NC2 was produced the same way except that the oligonucleotide SWI4-C was used instead of SWI4-B. 
FIG. 2 Defining SWI4's DNA-binding domain. a Deleted versions of SWI4 and a summary of their DNA binding. The black bar indicates the DNAbinding domain. Amino-acid end points are indicated by numbers on the right. $b$, Translation products of the above deletions. Size markers $(K)$ on the left. The low abundance of $\Delta 1$ might be a loading artefact. $c$, DNA-binding assays. Labelled probe $(0.5 \mathrm{ng})$ was incubated with $4 \mu$ l reticulocyte lysates containing the translation products of RNAs encoding viral coat proteins (lane 1) and SWI4 mutants ( $\Delta 1-\Delta 9$, lanes $2-10)$. fp, Free probe. d, SWI4 DNA binding is competed by oligonucleotides containing SCBs. Labelled probe $(0.5 \mathrm{ng}$ $\mathrm{pCL} 2$ ) was mixed with a control lysate (lane 11) and SWI4A6 (lanes 12-17). Unlabelled competitors were added at a 500 -fold molar excess in lanes 13-17. The oligonucieotide competitors are: unlabelled probe, $\mathrm{pCL} 2^{6}$ (lane 13 ); an $\mathrm{HO}$ promoter fragment containing three SCBs, sRS2 ${ }^{5}$ (lane 14); a TMP1 promoter fragment containing two MCBs, MCB-TMP1 ${ }^{8}$ (lane 15); an HO promoter fragment containing a SWI5-binding site ${ }^{26}$ (lane 16); and a fragment containing PREs bound by STE12 (lane 17) (M.P. and G. Ammerer, manuscript in preparation). Note that MCBs as well as SCBs can compete for binding. $e$, SWI4 8 : pCL2 gel retardation complexes are shifted by a SWI4 antibody. Labelled probe $(0.5 \mathrm{ng})$ was incubated with a control lysate (lane 18) and SWI $4 \Delta 8$ (lanes 19 and 20). A preimmune serum $(1 \mu \mathrm{l})$ and a SWI4 antiserum $(1 \mu l)^{8}$ were added in lanes 19 and 20 . Ternary complexes of DNA, SWI $4 \Delta 8$ protein and SWI4 antibody are marked $(a b 4+\Delta 8)$.

METHODS. As described for Fig. 1. Polymerase chain reaction (PCR) fragments with either ATG of TAA codons at the indicated amino acids were digested with Haell and Bg/II and ligated to an expression vector treated as described for SWI4 to yield SWI4 $\Delta 1-\Delta 5$; SWI $4 \Delta 6-\Delta 9$ has the termination codon from SWI $4 \Delta 3$ and were made by cloning PCR fragments cut with $\mathrm{NcOl}$ and $\mathrm{Bg} / \mathrm{Il}$ between the $\mathrm{NcOl}$ and $\mathrm{BamHI}$ sites of PT7 $7_{755-1024}$. The oligonucleotides used were: SWI4A1, tcgatcagatctITAGAACTGTTGAGGAGT; SWI4 $\Delta 2$, tcgatcagatceTTAATTCGCAGCTGTAGT; SWI4A3, tcgtcaagatctTAAATGTAGCTCGATGG; SWI4D4, tcgtcaagatetTAAAGTCTTCCTCAATAT; SWI4 5 , tcgatcagatctTTAATCGAATTGAAAAGT; SWI4 46 , actagaccATGGATAATACCAATCACCAG; SWI4D7, actagacCATGGTTCTTTTGGCGCCTCAT; SWI4 8 , actagaccATGGTGATTGAAATAGCTACG; SWI4 99 , actagaccATGGATGTATACGAATGCTATA.

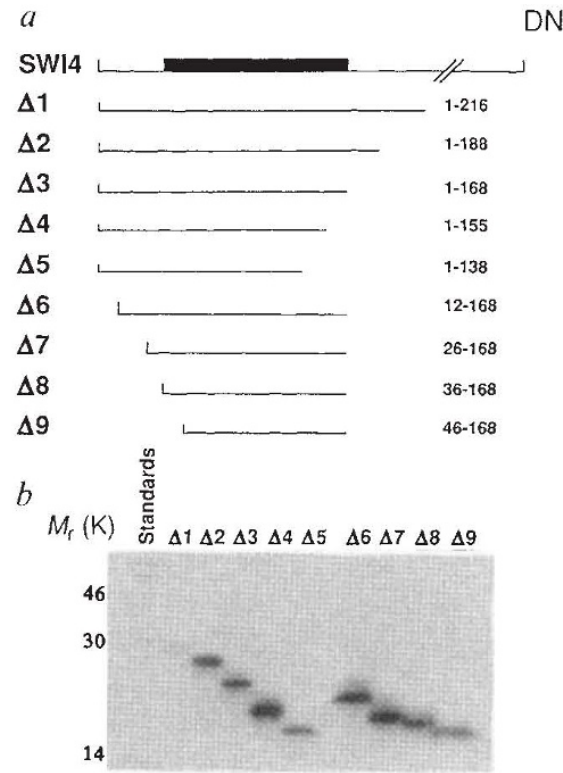

DNA binding $c$
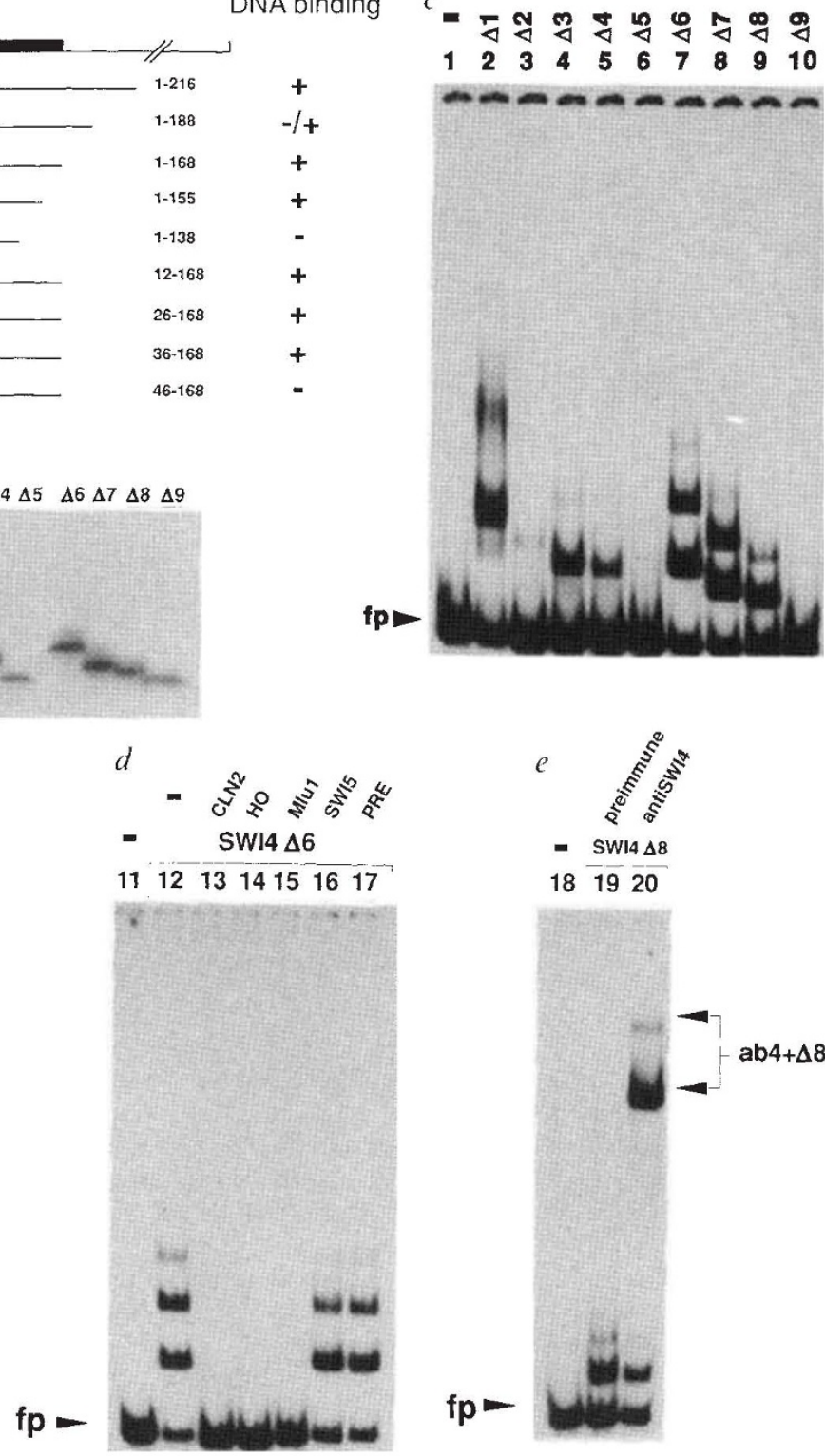

181920

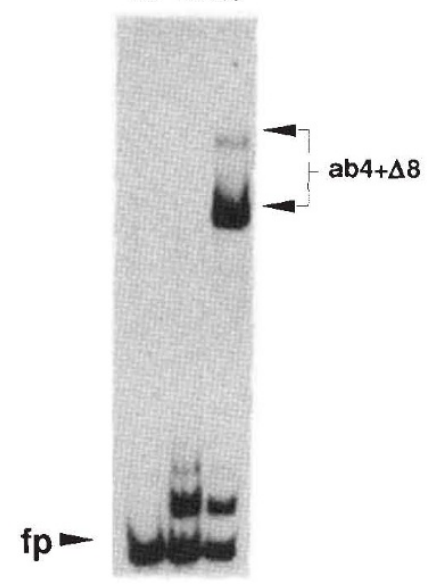

(M. Neuberg, personal communication) and is similar to an equivalent domain of the $c d c 10$ protein $(\mathrm{Cdc} 10)^{16}$.

To define SWI4's DNA-binding domain more precisely, we compared the binding activity of various truncated forms (Fig. $2 a$ ). SWI4 polypeptides lacking all amino acids C-terminal to position 155 can still form binary complexes, as can polypeptides lacking the $\mathrm{N}$-terminal 36 amino acids (Fig. $2 a, b, c$ ). But deleting $\mathrm{C}$-terminal to residue 36 or $\mathrm{N}$-terminal to residue 155 abolishes binding. A SWI4 polypeptide containing only residues 36 to $168(\Delta 8)$ forms complexes almost as efficiently as larger forms. The only anomaly of this deletion series is $\Delta 2$ which binds poorly. The complexes formed by $\Delta 8$ contain SWI4 protein (Fig. $2 e$ ) and those formed by $\Delta 6$ are competed by oligonucleotides containing SCBs from the CLN2 and $H O$ promoters but not by unrelated oligonucleotides (Fig. $2 d$ ). An oligonucleotide containing MCBs from the TMP1 promoter also competes. The amino acids 36-155 that form SWI4's DNA-binding domain are, in contrast to much of SWI4's primary sequence, highly conserved in a related protein for $\boldsymbol{K}$. lactis (M. Neuberg, personal communication) and are sufficient for binding to the $H O$ promoter in vivo ( $\mathrm{N}$. Jones, personal communication). But this domain alone cannot activate $\mathrm{HO}$ transcription ${ }^{17}$. Most of the SWI4 polypeptides capable of binding to pCL2 give rise to two and often three complexes. The number of complexes is related to the number of SCBs in the DNA (Fig. $3 a, c$ ). An oligonucleotide containing only a single SCB (pCL2 $\Delta 2$ ) forms only one type of complex with either SWI $4 \Delta 7$ or SWI $4 \Delta 8$, whereas an oligonucleotide containing two SCBs forms two types of complex (Fig. $3 a$ ). Cotranslation of SWI $4 \Delta 1$ and SWI $4 \Delta 8$ produced complexes with the expected mobilities but did not produce any complexes with an intermediate mobility indicative of hybrids (data not shown). These data imply that SWI4 binds as a monomer to single SCBs and that it can bind simultaneously to all three SCBs in pCL2. To determine the binding site of SWI4 on pCL2 22 more precisely, we have determined at which adenine or guanine residues carbethoxylation interferes with binding. Interference is restricted to bases in the original SCB consensus sequence ${ }^{20}$ (Fig. $3 b$ ). The pattern suggests that SWI4 makes contacts along an extensive stretch of the major groove.

To test whether SWI4's C terminus is sufficient for forming ternary complexes with SWI6 on DNA, we analysed complex formation with deleted versions of SWI4 lacking the central region due to fusion of SWI4's DNA-binding domain directly to C-terminal sequences. Neither the DNA-binding domain alone (data not shown) nor a fusion containing the C-terminal 65 residues (SWI4NC2) can recruit SWI6 but a larger fusion 


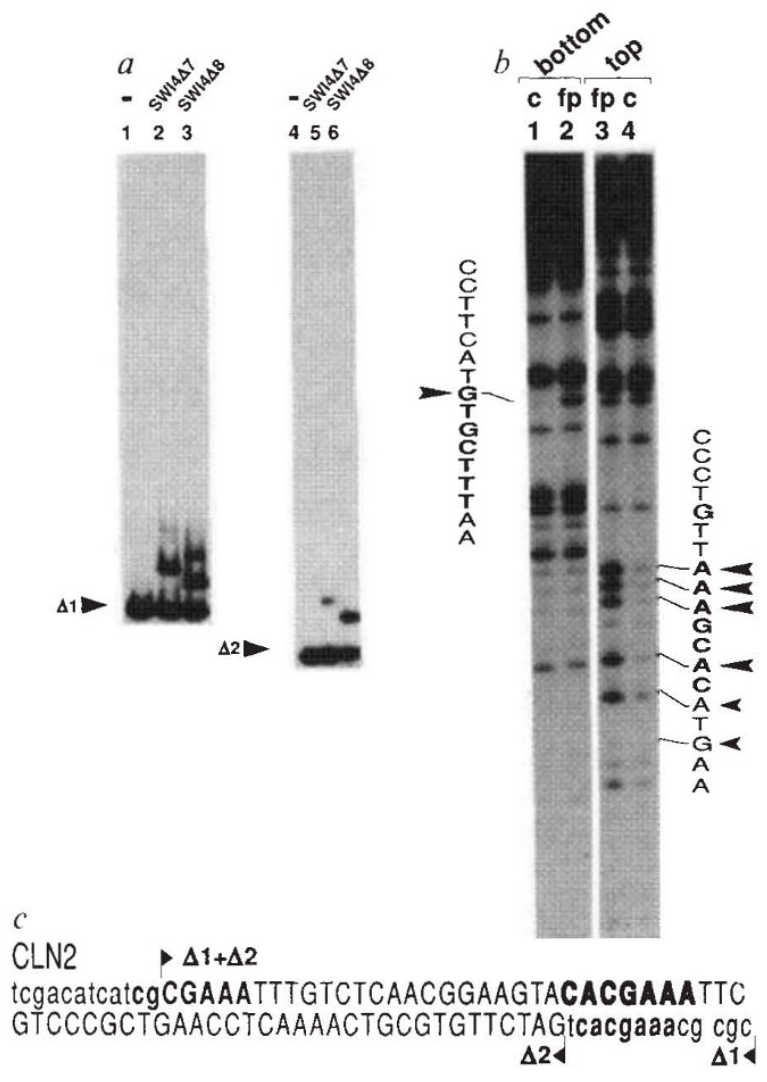

containing $146 \mathrm{C}$-terminal residues (SWI4NC1) allows SWI6 to form complexes on SCB DNA (Fig. $1 f$ ). Our data imply that SWI4's terminal 149 amino acids are both necessary and sufficient (with the DNA-binding domain) for recruiting SWI6 into ternary complexes in vitro but do not exclude other sequences also contributing.

We have found only a single protein that exhibits significant similarity to SWI4's DNA-binding domain. This is the Cdc10 protein from Schizosaccharomyces pombe ${ }^{21}$. A DIAGON comparison of SWI4 and Cdc10 (Fig. 4a) reveals two regions of similarity, one in the $\mathrm{N}$-terminus that has not previously been

FIG. 4 The region of SWI4 covering its DNA-binding domain is conserved in Cdc10 from S. pombe. The results of a DIAGON (a) and a peptide-sequence alignment $(b)$ obtained with the GCG package ${ }^{27}$. The sequences of SWI4 and Cdc10 were aligned with the BESTFIT program. The DOTPLOT parameters of the COMPARE program were window 35 with a stringency of 18.0. Identical residues and conservative changes are indicated by thick and thin lines, respectively. A SWI4 gene cloned and sequenced by us ${ }^{17}$ had an identical sequence to that published by Andrews and Herskowitz ${ }^{4}$. One problem with the proposal that the $\mathrm{N}$-terminal domain of Cdc10 may bind DNA is that a fragment of Cdc10 lacking this domain is capable at high copy number of suppressing the lethality of a temperature-sensitive Cdc10 mutant ${ }^{21}$. It is possible that the mutation whose phenotype is suppressed may lie in the C-terminal half of Cdc10 and the suppressing fragment may only enable the mutant protein with an intact DNA-binding domain to function.
FIG. 3 The SWI4's DNA-binding domain recognizes a single SCB element. a, End-labelled pCL2 21 ( $0.5 \mathrm{ng}$ ) (lanes 1-3) and pCL2 22 (lanes 4-6) probes were incubated with control lysates (lanes 1 and 4) as well as SWI4 47 (lanes 2 and 5) and SWI4 48 (lanes 3 and 6). b, Carbethoxylation interference $^{28}$. An end-labelled DEPC-treated ${ }^{8}$ oligonucleotide ( $\mathrm{pCL} 2 \Delta 2$ ) containing a single SCB from the CLN2 promoter was incubated with SWI4 48 . Unbound (fp, lanes 2 and 3 ) and complexed DNAs (c, lanes 1 and 4) were separated by gel electrophoresis as in $a$, and the hydrolysed products analysed on a $10 \%$ sequencing $\mathrm{gel}^{8}$. Interfering bases are indicated by arrowheads. $c$, The sequences of $\mathrm{pCL} 2, \mathrm{pCL} 2 \Delta 1$ and $\Delta 2$. The $\mathrm{pCL} 2$ sequence is shown on two lines and the end points of $\Delta 1$ and $\Delta 2$ are flagged. Large bases are those in pCL2 $\triangle 2$ whose SCB is in bold letters. Small bases are deleted at the $5^{\prime}$-end of pCL2 $2 \Delta 1$ or both at the $5^{\prime}$ - and $3^{\prime}$-end of PCL2 $2 \Delta 2$. recognized and a second in the middle of both proteins that corresponds to the two 33 amino acid 'Notch' repeats also found in SWI6 $6^{16}$ and many other proteins ${ }^{22,23}$. The $\mathrm{N}$-terminal region of similarity extends from residues 42 to 143 in SWI4, which corresponds almost exactly to its DNA-binding domain. Recently, Cdc10 has been shown to be part of a transcription factor ${ }^{13}$ that binds to the Start-dependent MCB element found in the promoters of many DNA replication genes in $S$. cerevisiae $^{9-12}$. We suggest that this region of $\mathrm{Cdc10}$ may be involved in the recognition of MCBs. It seems likely that the $S$. cerevisiae p120 protein that forms complexes with SWI6 on

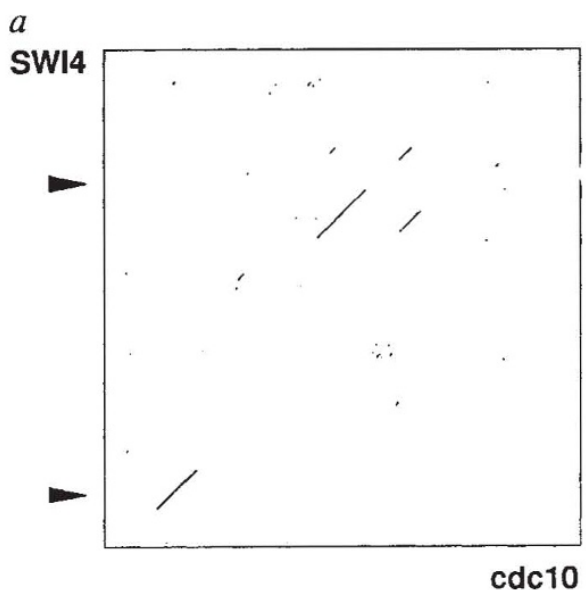

\section{SWI4}

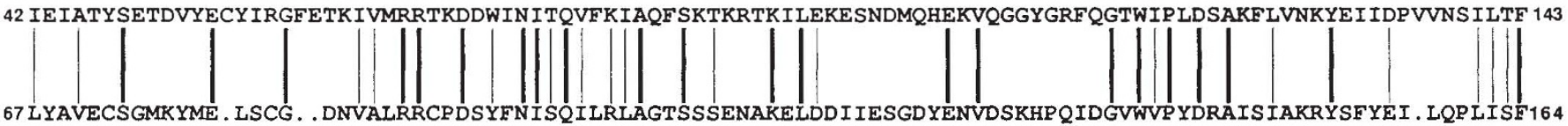


MCB elements ${ }^{8}$ will also turn out to have a similar DNA-binding domain. SCBs and MCBs are related in sequence and when present at high concentration can compete with each other for the binding of SWI4/SWI6 (SBF) and p120/SWI6 (MBF) complexes (ref. 8, Fig. $2 d$, and data not shown). Nevertheless, SBF and MBF bind preferentially to SCB and MCB elements, respectively ${ }^{6,8}$.

Apart from sharing two Notch repeats, the C-terminal half of Cdc10 is unlike that of SWI4. It instead has extensive similarity to the C-terminal half of SWI $6^{16}$. The Cdc10 protein therefore has the appearance of a hybrid between SWI4 and SWI6. In

Received 8 April; accepted 18 June 1992.

1. Richardson, H, E., Wittenberg, C., Cross, F. \& Reed, S. I. Cell 59, 1127-1133 (1989).

2. Wittenberg, C., Sugimoto, K. \& Reed, S. I. Cell 62, 225-237 (1990).

3. Breeden, L. \& Nasmyth, K. Cell 48, 389-397 (1987).

4. Andrews, B. J. \& Herskowitz, I. Nature 342, 803-833 (1989)

5. Taba, M. R., Muroff, 1., Lydall, D., Tebb, G. \& Nasmyth, K. Genes Dev, 5, 2000-2013 (1991)

6. Nasmyth, K. \& Dirick, L. Cell 66, 995-1013 (1991).

7. Ogas, J., Andrews, B. J. \& Herskowitz, I. Cell 66, 1015-1026 (1991)

8. Dirick, L., Moll, T., Auer, H. \& Nasmyth, K. Nature 357, 508-513 (1992).

9. Pizzagalli, A., Valsasnini, P., Plevani, P. \& Lucchini, G. Proc. natn. Acad. Sci. U.S.A. 85, 3772-3776 (1988)

10. Mclntosh, E. M., Atkinson, T., Storms, R. K. \& Smith, M. Molec. cell. Biol. 11, 329-337 (1991). 11. Gordon, C. B. \& Campbell, J. L. Proc. natn. Acad. Sci. U.S.A. 88, 6058-6062 (1991).

12. Lowndes, N. F., Johnson, A. L. \& Johnson, L. M. Nature 350, 247-250 (1991)

13. Lowndes, N. F., Mclnerny, C. J., Johnson, A. L., Fantes, P. A. \& Johnston, L. H. Nature 355, 449-453 (1992).

14. Nurse, P., Thuriaux, P. \& Nasmyth, K. Molec. Gen. Genet. 146, 167-178 (1976).

15. Nurse, P. \& Bisset, Y. Nature 292, 558-560 (1981).

16. Breeden, L. \& Nasmyth, K. Nature 329, 651-654 (1987). contrast to Cdc10, the $\mathrm{N}$ terminus of SWI6 has very little resemblance to SWI4. It may therefore not possess a functional DNA-binding domain, which is consistent with it not binding DNA in in vitro assays (Fig. $1 b$ ). One explanation for the hybrid character of Cdc10 is that all of these proteins are descended from a Cdc10-like ancestor, one of whose descendants (SWI4) has, apart from the Notch repeats, diverged extensively in its $\mathrm{C}$ terminus and another (SWI6) has diverged extensively in its $\mathrm{N}$ terminus. The conservation of SWI4's DNA-binding domain suggests that it may be found in Start-dependent transcription factors in many eukaryotic organisms.

17. Sockanathan, S. thesis, Univ. Cambridge (1991).

18. Breeden, L. \& Mikesell, G. E. Genes Dev, 5, 1183-1190 (1991).

19. Moll, T., Dirick, L., Auer, H. \& Nasmyth, K. J. Cell Science (in the press).

20. Nasmyth, K. Cell 42, 213-223 (1985).

21. Aves, S. J., Durckacz, B. W., Carr, A. \& Nurse, P. EMBO J. 4, 457-463 (1985)

22. Lux, S. E., John, K. M. \& Bennett, V. Nature 344, 36-42 (1990).

23. Thompson, C. C., Brown, T. A. \& MCKnight. S. L. Science 253, 726-768 (1991)

24. Laemmli, U. K. Nature 227, 680-685 (1970).

25. Van der Werf, S. et al. Proc. natn. Acad. Sci. U.S.A. 83, 2330-2334 (1986)

26. Stillman, D. J., Bankier. A. T., Seddon, A., Groenhout, E. G. \& Nasmyth, K. EMBO J. 7, 485-494 (1988).

27. Devereux, J., Haeberli, P. \& Smithies, O. NAR 12, 387-395 (1984).

28. Sturm, R., Baumruker, T., Franua, B. R. \& Herr, W. Genes Dev. 1, 1147-1160 (1987)

ACKNOWLEDGEMENTS. We thank $H$. Tkadletz for help in preparing the figures, $R$. Kurzbauer and $G$. Schaffner and co-workers for oligonucleotide synthesis and DNA sequencing. M. Nicklin for providing T7 RNA polymerase, T. Moll for antibodies against SW14,C. Koch, B. Errede and L. Ballou for comments on the manuscript, G. Ammerer in whose laboratory this work was done and encouraged and R. Treisman for plasmid PT7 $755-1024$. M.P. was supported by an FWF grant to G.A. This work was supported by the Austrian Industrial Research Promotion Fund.

\section{Candidate proto-oncogene bcl-3 encodes a subunit-specific inhibitor of transcription factor NF- $\kappa$ B}

\section{F. Gregory Wulczyn, Michael Naumann \& Claus Scheidereit*}

Otto Warburg Laboratorium, Max Planck Institut für Molekulare Genetik, Innestrasse 73, 1000 Berlin 33, Germany

THE NF- $\kappa$ B subunits $\mathrm{p50}$ and $\mathrm{p} 65$ and the product of the rel proto-oncogene are members of a growing class of transcription factors with a unique DNA-binding and dimerization domain ${ }^{1-13}$. Nuclear transfer of each of these factors is controlled by cytoplasmic inhibitors, and regulated by specific stimuli. The inhibitors $I \kappa B-\alpha$ and $-\beta$ and $\mathrm{pp} 40$ recognize either $\mathrm{p} 65$ or the c-rel pro$\operatorname{tein}^{14-16}$. We show here that the proto-oncogene $b c l-3$, believed to be involved in certain human $B$-cell leukaemias ${ }^{17}$, encodes a protein that functions as an I $\kappa$ B-like molecule for native NF- $\kappa$ B but is specific for the p50 subunit. The ankyrin repeat domain of the $b c l-3$ product is shown to mediate complex formation with NF- $\kappa B$ dimers by contacting the conserved dimerization domain of NF- $\kappa$ B.

On the basis of structural similarities in a repeat domain of the $b c l-3$ protein $(\mathrm{Bcl}-3)$ and a region in the $\mathrm{C}$-terminal domain of p105 (refs 3-6) and MAD-3/I $\kappa$ B- $\alpha$ (ref. 18), we predicted as a common function the interaction with Rel-like transcription factors and reported that DNA binding of p50 is inhibited by the repeat domain of p105 and by Bcl-3 (ref. 19). We now report that native $\mathrm{NF}-\kappa \mathrm{B}$ is a target for $\mathrm{Bcl}-3$.

In a band-shift assay with nuclear extracts from HeLa cells, Bcl-3 specifically inhibited nuclear NF- $\kappa$ B induced with the phorbol ester phorbol myristate acetate (PMA) (Fig. 1 $a$, lanes 3 and 4), but did not affect endogenous octamer-binding transcription factor 1 (OTF-1) binding (lanes 5,6$)$. The inhibition

was achieved using an amount of Bcl-3 comparable to the amount of MAD-3/I $\kappa \mathrm{B}$ (ref. 18) necessary for inhibition of native NF- $\kappa$ B (not shown), demonstrating that Bcl-3 is an alternative form of $\mathrm{I} \kappa \mathrm{B}$. We next analysed the subunit specificity of Bcl-3 for various Rel-like factors. DNA binding of p50, or of truncated p50 containing only the conserved Rel domain

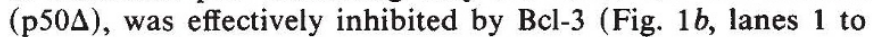
$4)$. Both the c-rel protein and truncated p65 were recognized (lanes 5 to 8), but less efficiently. In contrast, the Drosophila morphogen dorsal was not a target (lanes 9, 10). The affinities of Bcl-3 and MAD-3/I $\kappa \mathrm{B}$ were compared for both subunits of $\mathrm{NF}-\kappa \mathrm{B}$ (Fig. $1 c$ ). MAD-3 has a strong preference for p65, but can at high concentrations also inhibit p50 (lanes 5-8, 13-16). Bcl-3 clearly has an inverse specificity, with a higher affinity for p50 than for p65 (lanes 1-4, 9-12). These results establish that Bcl-3 is a previously undetected $I \kappa \mathrm{B}$ species with a novel specificity, and suggest that $\mathrm{I} \kappa \mathrm{B}$ molecules recognize the Rel domain in a conserved manner.

A deletional analysis of the Bcl-3 molecule (Fig. 2) revealed that the ankyrin repeat domain is necessary and sufficient for inhibition (Fig. $2 b$, lanes 1 to 4 ), and that removal of either part of the first repeat (lanes 5 and 6), or of the seventh and part of the sixth (lanes 7 and 8), results in inactivation. This is in contrast to erythrocyte ankyrin and GA binding protein $\beta$ in which a subset of the ankyrin repeats can mediate protein-protein interaction $^{20,21}$, but is similar to the ankyrin repeat domains of $\mathrm{p} 105$ and MAD-3 (ref. 19; and E. Hatada and C.S., unpublished observation).

To determine which domain of p50 is contacted by $\mathrm{Bcl}-3$, deletion mutants of $\mathrm{p} 50$ were assayed for interaction with immobilized Bcl-3 (Fig. 3). At the $\mathrm{C}$ terminus, amino acids up to and including the conserved nuclear transfer signal could be deleted (p50 $\mathrm{p}$ and $\mathrm{C} 1$ ) without affecting binding to the Bcl-3 matrix, but further deletion of $18(\mathrm{C} 2)$ or $38(\mathrm{C} 3)$ amino acids abrogated interaction (Fig. $3 b$ ). For unknown reasons, Nterminal deletions led to low levels of nonspecific binding to the control matrix (N2 and N3). Nevertheless, deletion of either the N-terminal 75 (N1) or 201 (N2) amino acids did not reduce binding to Bcl-3 compared to full-length p50; and the level of specific binding was significantly higher than to the immobilized 